\title{
Yarı kurak ve tuzlu/jipsli alanlarda farklı arazi hazırlığı yöntemlerinin fidan gelişimine etkileri
}

The effects of different field land preparation techniques on seedling development in semi-arid and salted/gypsy areas

\author{
Yakup ÖZ' \\ Ceyhun GÖL ${ }^{1}$
}

${ }^{1}$ Çankırı Karatekin Üniversirtesi, Orman
Fakültesi, Çankırı

Sorumlu yazar (Corresponding author) Ceyhun GÖL

drceyhungol@gmail.com

Geliş tarihi (Received)

28.01.2021

Kabul Tarihi (Accepted)

11.03.2021

Sorumlu editör (Corresponding editor) Şükrü Teoman GÜNER

stguner@gmail.com

Atıf (To cite this article): Öz, Y, Göl, C . (2021) Yarı kurak ve tuzlu/jipsli alanlarda farklı arazi hazırlığı yöntemlerinin fidan gelişimine etkileri Ormancillk Araştırma Dergisi , 8 (2) , 146-156 . DOI: $10.17568 /$ ogmoad. 870211

\section{Öz}

Çalışmada, yarı kurak iklim ve tuzlu/jipsli toprak özelliklerine sahip bir bölgede ağaçlandırma ve erozyon kontrolü amaçlı uygulanan fark11 toprak işleme yöntemlerinin fidan çap/boy gelişimi üzerine etkileri incelenmiştir. Örnekleme çalışmaları $400 \mathrm{~m}^{2}$ alanlarda veya bu alanlar içine giren $300 \mathrm{~m}$ teraslar üzerinde yapılmıştır. Beş farklı toprak işleme parseline dikilen dört farklı ağaç türüne ait fidanların çap/ boy gelişimi ve morfolojik özellikleri incelenmiştir. Yalancı akasya türünün en yüksek çap ve boy ortalamasına, BUROR teras arazi hazırlığının ise birim alanda yaşayan fidan sayısı ve fidan gelişimi bakımından en yüksek başarı ortalamasına sahip olduğu belirlenmiştir. Çukur dikim ile üst toprak işleme+çukur dikim aynı fidan gelişim özelliği göstermiş̧tir. İbreli türler içerisinde sedir en düşük, kızılçam ise en yüksek fidan gelişimi göstermiştir.

Anahtar Kelimeler: Tuz, jips, fidan, kuraklık, arazi hazırlığı, ağaçlandırma, ağaç türleri

\begin{abstract}
In this study, the effects of different soil preparation techniques applied for afforestation and erosion control on seedling diameter/height growth in a region with a semi-arid climate and salty/gypsum soil properties were investigated. Sampling studies were carried out in $400 \mathrm{~m}^{2}$ areas or $300 \mathrm{~m}$ terraces on these areas. Seedling morphological characteristics and diameter/height growth of four different tree species planted in five different tillage plots were examined. It was determined that the black locust species had the highest average diameter and height, and the BUROR terrace field preparation had the highest average success in terms of the seedling survival and growth. As a result, seedlings planted with pit planting method showed the similar performance to those of planted with topsoil cultivation+pit method. Among the coniferous species, cedar showed the lowest growth rate, while red pine showed the highest.
\end{abstract}

Keywords: Salt, gypsum, seedling, drought, land preparation, planting, tree species 


\section{Giriş}

Bugün dünyada en önemli çevre sorunları olan kuraklık ve erozyon insanlığı açlığa, yoksulluğa, susuzluğa ve göçe zorlamaktadır. Özellikle kurak alan ağaçlandırma çalışmaları, kuraklık ve erozyonla mücadelede büyük önem taşımaktadır. Kurak bölge ağaçlandırma çalışmalarında iklim, toprak, ağaç türü seçimi dikim başarısını doğrudan etkilemektedir. Buna göre Türkiye'de kurak ve yarı kurak alanlar ve buralardaki tuzlu/jipsli sahalar, ağaçlandırma için en olumsuz özelliklere sahiptir. $\mathrm{Bu}$ ağaçlandırma sahalarında başarıyı artırmak için proje başlangıcındaki etüt çalışmaları dikkatle yapılmalıdır. Ağaçlandırılacak sahanın ekolojik özellikleri (iklim, toprak, topoğrafya, vb.) çok özenle incelenmeli, çalışmalar bu özelliklere göre şekillendirilmelidir (Kantarcı ve ark., 2010a; Kantarc1 ve ark., 2010b; Boydak ve ark., 2014).

Çankırı-Sivas arasında jipsli araziler üzerinde yer yer tuzlu ve boz renkli topraklar yaygındır (ÇEM, 2013). Araştırmanın yürütüldüğü bölge kurak/yarı kurak özellikte ve tuzlu/jipsli ana kaya yapısındadır. Bu özellikleri ile ağaçlandırma çalışmalarının yürütüleceği en zorlu sahalardan biri olarak karşımıza çıkmaktadır. Tuzlu topraklar özellikle kurak-yarı kurak bölgelerde yaygın olarak bulunan ve bitki gelişimine engel olacak miktarda çözünebilir tuz içeren topraklardır (Güneş ve ark., 2010) Tuz stresi bitkilerde iki şekilde ortaya çıkar. Birincisi, bitkinin suyu topraktan alamaması, ikincisi ise zehirleyici etki oluşturmasıdır (Yang ve ark., 1990). Türkiye'nin yarı kurak alanlarındaki topraklar genellikle ince tekstürlü, kireçli, hafif alkali, sığ ve iskeletli özelliklerdedir. Tuzlu, alkali veya jipsli topraklarda $\mathrm{pH}$ değerleri orta veya yüksek düzeyde olabilmektedir (Atalay, 2015).

Dünya'da jips (alçıtaş1), kurak ve yarı kurak bölgelerde oldukça geniş alanlarda (yaklaşık 100 milyon hektar) yayılış göstermektedir (FAO, 1990; Oyonarte ve ark., 2002; Mota ve ark., 2003; Akpulat ve Çelik, 2005; Pueyo ve ark., 2007; Palacio ve ark., 2007; Cañadas ve ark., 2013). Jips içeriği \%22'den fazla olan topraklar jips içeren topraklar olarak adlandirılmaktadir (Alphen ve Rios- Romero, 1971). Jipsli topraklar (Gypsisoller) genellikle yıllık yağ1ş1n 400 mm'den düşük olduğu ve jips kaynaklar1nın bulunduğu kurak ve yarı kurak alanlarda gelişirler (FAO, 1990).

Türkiye'de yukarıda verilen tanımlamaya uyan İç Anadolu Bölgesinde, geniş tuzlu/jipsli topraklar yayılış göstermektedir. Çankırı ili sınırları içerisinde toprakların en üst kısmında dikkati çeken fasiyes beyaz jipsli marndır. Bozkır Platosu, Çankırı ili, Acıçay aşağı boyları, Tüney-Çankırı ve
Kaya Tuzu Mağarası-Çankırı arasında muntazam tabakalı ve azami kalınlıktadır (Gökmen, 2007). Jips içeren topraklar bitki yaşamı için fiziksel ve kimyasal stres ortamı yaratmaktadır. Jipsli topraklarda bitki gelişimini sınırlayıcı kimyasal faktörler makro ve mikro besin elementi yetersizliği veya bazı besin elementlerinin fazlalığ 1 olarak ortaya çıkmaktadır. Fiziksel sınırlayıcı faktörler ise toprak yüzeyinde kabuk oluşumu, yüksek su çekme ile düşük infiltrasyon ve perkolasyondur (Meyer, 1986).

$\mathrm{Bu}$ araştırma, yarı kurak iklim özelliklerine sahip, tuzlu/jipsli bir alanda 1- farklı toprak işleme yöntemlerinin fidan gelişimi üzerine etkilerini, 2- dikimi yapılan ibreli/yapraklı tür fidanlarının başarı kontrolünü ve 3- fidanların tutma ve gelişme başarısını ortaya koymak amacıyla yapılmıştır.

\section{Materyal ve Yöntem}

\subsection{Araştırma alanının tanıtımı}

Araştırma alanı Çankırı ili, merkez ilçe sınırları içerisinde, Çankırı Oto Sanayii ile Çankırı 28. Mekanize Piyade Tugay Komutan Yardımcılığı arazisi arasında yer almaktadır. Çankırı ili, Orta Anadolu'nun kuzeyinde Kızılırmak ve Batı Karadeniz ana havzaları içerisinde yer alır (OGM, 2013). İl topraklar1 40³0'41" kuzey enlemleri ile 32॰30'34" doğu boylamları arasında kalmaktadır. İlin denizden yüksekliği 723 m'dir (Şekil 1).

Araştırma alanı örnekleme noktaları, 2013 yılında Ankara Orman Bölge Müdürlüğü, Çankırı Orman İşletme Müdürlüğü, Çankırı İşletme Şefliği (404 Numaralı Bölmede) "28. Mekanize Piyade Tugay Komutan Yardımcılığı Erozyon Kontrolü Uygulama Projesi” adı altında 203,77 hektar alanda yürütülen proje sahası içerisinde belirlenmiştir. $\mathrm{Bu}$ saha Tüney-Çankırı tuzlu/jipsli bölgesi içerisinde kalmaktadır.

Araştırma alanının deniz seviyesinden yüksekliği 700-825 m arasındadır. Örnekleme alanları ise 731783 m yükselti basamağ içerisindedir (Tablo 1 ve Şekil 2). Araştırma alanı içerisinde altı farklı eğim sınıfı vardır. Örnek alanların eğim sınıfı ise düşük (\%0-5), orta (\%5-12), yüksek (\%12-20) ve çok yüksek (\% 20-40) eğimli alanlardan oluşmaktadır. Araştırma alanının \% 66'sı doğu ve kuzey-güney doğu bakıdadır. Alanın \%10’u düz, \%17'si ise güney bakıdadır. Örnekleme noktalarının tümü doğu bakıdadır (Tablo 1 ve Şekil 3).

Araştırma alanının içinde bulunduğu İç Anadolu bölgesinde yazları sıcak, kışları soğuktur. Doğal bitki örtüsü, yaz kuraklığından dolayı alçak kı- 


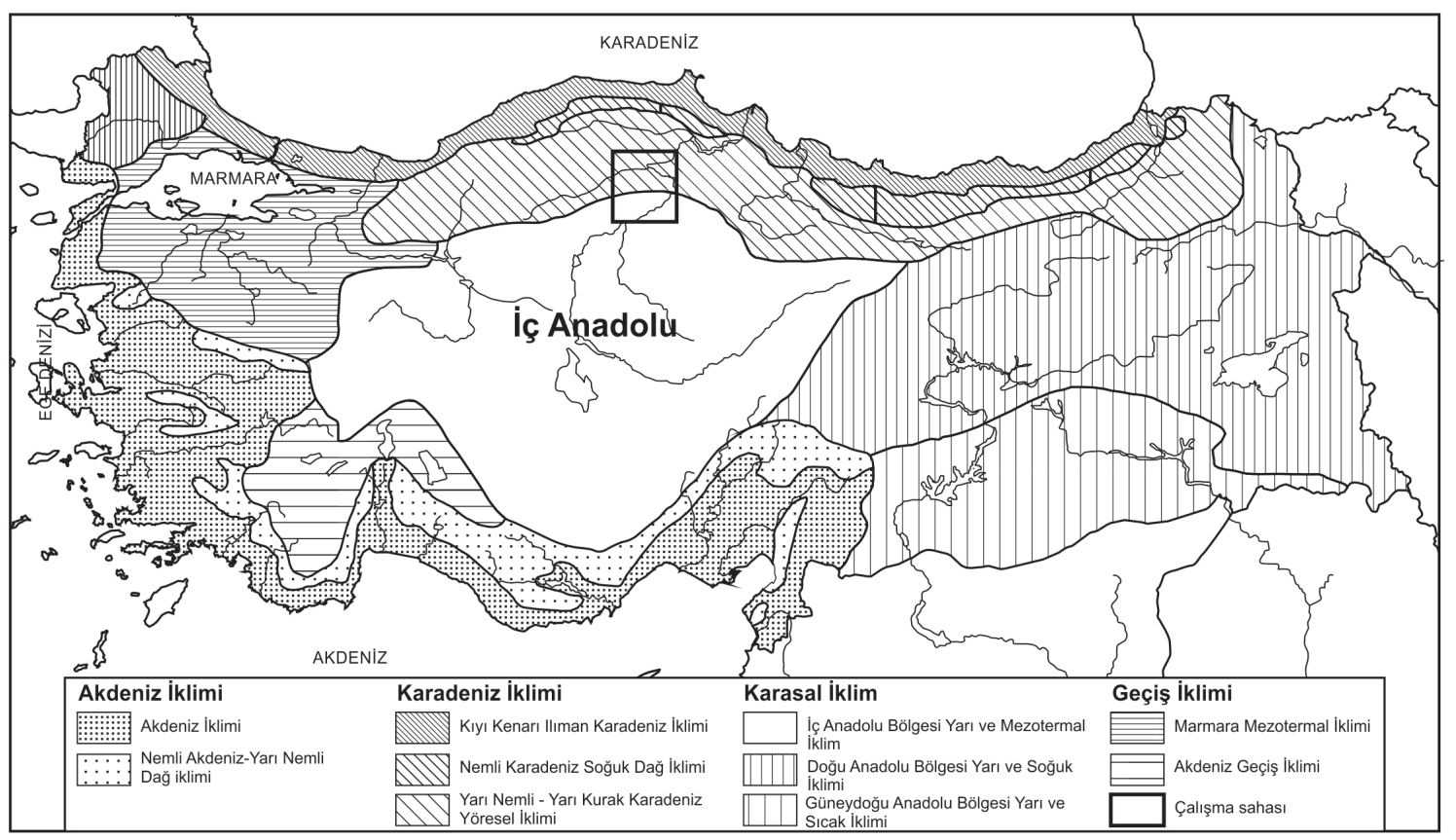

Şekil 1. Türkiye ekolojik bölgeleri ve araştırma alanı (Atalay, 2014)

Figure 1. Turkey's ecological zones and research area

sımlarda bozkırlardan, yüksek kesimlerde ise kuru ormanlardan oluşur. Araştırma alnında yıllık ortalama sıcaklık $10,8^{\circ} \mathrm{C}$, ortalama yıllık toplam yağ $1 s ̧$ 413,8 mm dir (MGM, 2019). Thornthwaite iklim sınıflandırma modeline göre Çankırı D B' $1 \mathrm{~d}$ b' 3 rumuzu ile gösterilen "Kurak-yarıkurak, mezotermal, su fazlası yok veya pek az, denizel iklim etkisine yakın" bir iklim sınıfındadır (Göl, 2002).

Çankırı ili toprakları, Karadeniz Bölgesi ve Orta Anadolu Bölgesi olarak hemen hemen iki eşit parçaya bölünür (Gökmen, 2007). Çankırı ilinin kuzeyi III. Zamanda oluşmuş Oligosenmiyosen yaştaki jips serileri ile kaplıdır. Bu seri kuzeydoğuda Yapraklı ilçesi, güneydoğuda Kızılırmak, güneyde Ankara il sınırı, güneybatıda Eldivan ilçesinin sınırladığı geniş bir alana yayılmıştır. Bu oluşum kalın ve k1rmızı renkli bir taban konglomerası ile başlar; bu açık renkli ve aralarında jips yatakları da bulunan kil ve marnlar izler. Jips serisinin üst kesimleri birçok yerde miyosen oluşumları da içerir. $\mathrm{Bu}$ yapılanma, Eosenden sonra denizin bu bölgeden tümüyle çekildiğini ve yörede bir çöl ikliminin egemen olduğunu kanıtlamaktadır (Blumenthal, 1948; Birgili ve ark., 1975; Akyürek ve ark., 1988).

Araştırma alanında tuzlu ve jipsli anakayalardan oluşmuş bir toprak yapısı bulunmaktadır. Mutlak derinlik oldukça yetersiz iken jipsli ana kayanın karst yapısından kaynaklanan çatlak sistemine bağlı olarak fizyolojik derinlik yüksektir. Jipsli bölge toprakları kil ve marnlarla birlikte bulunurlar. Buna bağlı olarak kil kapasitesi oldukça yük- sek killi topraklardan oluşmaktadır.

Araştırma alanı, Türkiye'nin üç büyük flora alanlarından İran-Turan flora bölgesinde yer almaktadır.

Araştırma alanı, Karadeniz nemli iklim kuşağından Orta Anadolu kurak iklim kuşağına geçiş zonu içerisinde yer almaktadır. Karadeniz ikliminin etkisi altında kalan yüksek dağlık bölgelerde kuru ormanlar ve geniş mera alanları, İç Anadolu kurak iklimin hakim olduğu bölgelerde ise bozkır bitki örtüsü hakimdir. Ayrıca araştıma alanının da içinde bulunduğu bölgede ana kayanın tuz/jips olması bitki örtüsünü olumsuz etkilemektedir. Bu alanlarda oldukça zayıf otsu türler geniş alanlarda yayılış göstermektedir. Çankırı ilinde geniş alanlar antropojen bozkır bitki örtüsü ile kaplanmıştır. Geçiş kuşağında yer alan ağaç ve çalı türleri; Sarıçam (Pinus sylvestris L.), kızılçam (Pinus brutia Ten.), Anadolu karaçamı (Pinus nigra Arnold. subsp. pallasiana (Lamb) Halmboe) ve Toros sediri (Cedrus libani A. Rich), yalancı akasya (Robinia pseudoacacia L.), katran ardıc1 (Juniperus oxycedrus L. subsp. oxycedrus), baklagiller (Leguminosae spp.), kuşburnu (Rosa canina L.), ahlat (Pyrus elaeagnifolia Pallas), alıç (Crataegus monogyna L.) ve karaçalı (Paliurus spinachristi Mill.)'dır (Göl, 2002; OGM, 2011-2030).

Araştırma alanı, Türkiye'nin Önemli Bitki Alanı (ÖBA)'ndan 89. sırada bulunan 'Çankırı'nın Jipsli Tepeleri” alanı içerisindedir. ÖBA, Kızılırmak’ın Kuzeyinde, Çankırı şehir merkezine yakın geniş 
jips çökeltileri üzerindedir. ÖBA florası zengin bitki çeşitliliği göstermez ve bozkır ile mezotrofik mera habitatlarının bir mozaiğini oluşturur. ÖBA florasında, Türkiye'ye endemik 41 takson yer alır.
ÖBA resmi olarak koruma altında değildir, otlatma ve tarıma dönüştürme alanı tehdit etmektedir (Tuttu ve Akkemik, 2017; Atay ve ark., 2021).

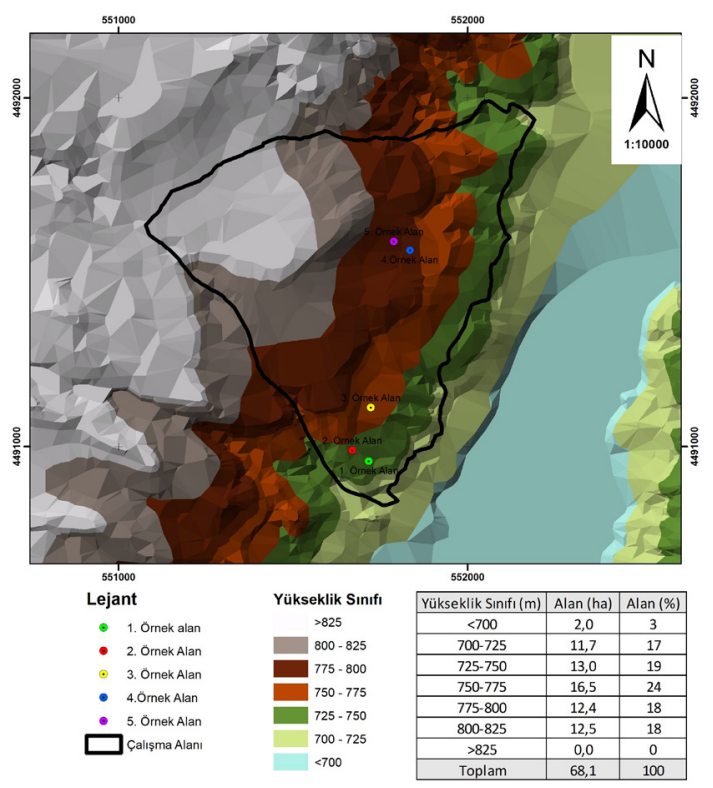

Şekil 2. Araştırma alanının yükselti haritası Figure 2. Elevation map of the research area

Tablo 1. Araștırma alanın yetișme ortamı etüt tablosu Table 1. Habitat study table of the research area

\begin{tabular}{|c|c|c|c|c|c|c|c|c|c|c|c|c|c|}
\hline \multirow{2}{*}{\multicolumn{2}{|c|}{$\begin{array}{c} \\
\text { Örnek Alan / } \\
\text { Toprak Çukur } \\
\text { Noktası }\end{array}$}} & \multicolumn{12}{|c|}{ Araștırma Alan1 Yetișme Ortamı Etüt Tablosu (Fizyoğrafik ve Genel Toprak Özellikleri) } \\
\hline & & \multirow{2}{*}{ 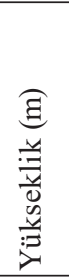 } & \multirow[b]{2}{*}{$\frac{\bar{z}}{\tilde{\Xi}}$} & \multirow[b]{2}{*}{ 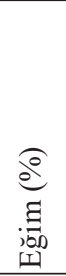 } & \multirow{2}{*}{ 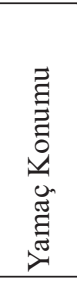 } & \multirow{2}{*}{ 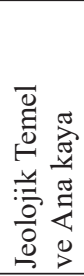 } & \multicolumn{4}{|c|}{$\begin{array}{c}\begin{array}{c}\text { Toprak Derinliği } \\
(\mathrm{cm})\end{array} \\
\text { Mutlak (M) } \\
\text { Fizyolojik (F) }\end{array}$} & \multirow{2}{*}{ 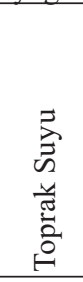 } & \multirow{2}{*}{\multicolumn{2}{|c|}{$\begin{array}{c}\text { Dikilen Fidan Orijinleri,Türü ve } \\
\text { Yaş1 }\end{array}$}} \\
\hline No & $\begin{array}{c}\text { Koordinat } \\
\text { (UTM) } \\
\text { X-Y }\end{array}$ & & & & & & ô & $\begin{array}{l}8 \\
\frac{1}{m} \\
m\end{array}$ & $\frac{\overbrace{}}{\frac{1}{6}}$ & $\stackrel{v}{\circ}$ & & & \\
\hline 1 & $\begin{array}{r}551738 \\
4491143\end{array}$ & 731 & Doğu & 36 & 䓛 & $\overbrace{=}^{\infty}$ & & $\mathrm{F}$ & M & & 䔍 & $\begin{array}{l}\text { Kızılçam } \\
\text { Akasya: } 1\end{array}$ & $\begin{array}{l}\text { : Anamur/Mersin, tüplü, } \\
\text { 2+0, Y. } \\
\text { Tokat, çıplak köklü, } 1+0 \text {, }\end{array}$ \\
\hline 2 & $\begin{array}{r}551689 \\
4491170\end{array}$ & 735 & Doğu & 17 & 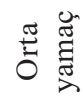 & $\cong$ & & & F-M & & 莺 & K1z1lçam & $\begin{array}{l}: \text { Anamur/Mersin, tüplü, } \\
2+0\end{array}$ \\
\hline 3 & $\begin{array}{r}551800 \\
4491709\end{array}$ & 783 & Doğu & 20 & 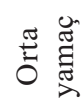 & $\cong$ & & $\mathrm{F}$ & M & & 芯 & $\begin{array}{l}\text { Karaçam } \\
\text { Sedir }\end{array}$ & $\begin{array}{l}\text { : İsmetpaşa, tüplü, } 2+0 \\
\text { : Ermenek, tüplü, } 2+0\end{array}$ \\
\hline 4 & $\begin{array}{r}551903 \\
4491706\end{array}$ & 778 & Doğu & 10 & 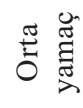 & 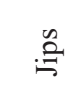 & & & $\mathrm{F}$ & M & 荎 & Karaçam & : İsmetpaşa tüplü $2+0$ \\
\hline 5 & $\begin{array}{r}551776 \\
4491311\end{array}$ & 758 & Doğu & 11 & 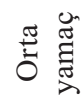 & $\cong$ & M & $\mathrm{F}$ & & & 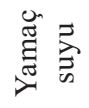 & Karaçam & : İsmetpaşa tüplü $2+0$ \\
\hline
\end{tabular}

Örnekleme noktaları orta yamaçta, drenaj sorunu bulunmayan, mutlak toprak derinlikleri orta (61$120 \mathrm{~cm}$ ) sinıf, fizyolojik toprak derinlikleri ise yetersiz $(31-60 \mathrm{~cm})$ ve orta $(61-120 \mathrm{~cm})$ siniflarda yer almaktadır. Bu noktalarda dikilen fidanlar dışında vejetasyon otsu türler ile kaplıdır (Tablo 1). Araştırma alanı bozuk orman niteliği taşımakdır. 


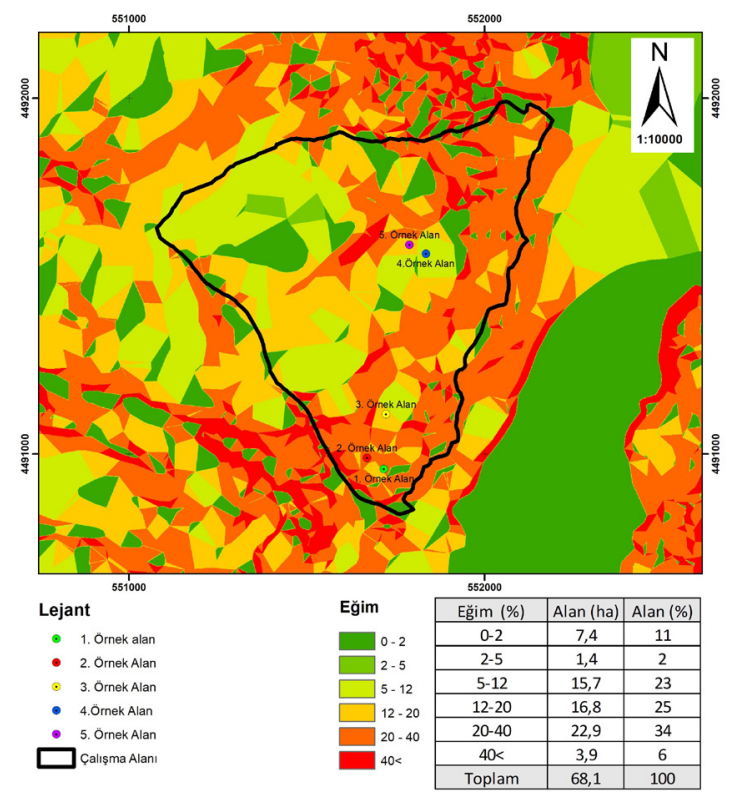

Şekil 3. Araştırma alanının eğim haritası Figure 3. Slope map of the research area

\subsection{Yöntem}

Araştırma alanına ait topografik, jeolojik, meşcere, toprak ve dikim haritaları ile iklim verileri elde edilmiştir. Bu veriler 1şığında, alanın Sayısal Yükselti Modeli (SYM) (Şekil 2) kullanılarak alanda yayılım gösteren farklı eğim grupları, fizyografik üniteler, rölyef ve bak1 grupları belirlenmiştir. Harita ve iklim verileri üzerinde çalışılarak araştırmanın amacına uygun alanlar belirlenmiştir. Değişik zamanlarda yapılan ön arazi etütleri sonucunda da amaca en uygun dikim sahaları ve örnekleme noktaları belirlenmiştir.

Araştırma alanının da içinde bulunduğu erozyon kontrol proje sahasında 1- ikili riperli paletli dozer ile alt toprak işlemesi, 2- ikili riperli paletli dozer ile alt toprak işlemesi + çift soklu pulluk ile üst toprak işlemesi, 3- mini ekskavatör ile BUROR teras $(150 \mathrm{~cm})$ şeklinde toprak işleme, 4- mini ekskavatör ile dikim çukuru açma çalışmaları yürütülmüştür.

Toprak hazırlığı yapılan sahalarda kızılçam, yalanc1 akasya, Anadolu karaçamı ve Toros sediri türleri ile dikim şeklinde ağaçlandırma yapılmıştır.

$\mathrm{Bu}$ sahalar içerisinden benzer ekolojik koşullara sahip, farklı arazi hazırlığı çeşitleri (toprak işleme şekli) ve dikilen ağaç türü dikkate alınarak beş örnekleme alanı belirlenmiştir.

Belirlenen örnek alanların $\left(20 \times 20=400 \mathrm{~m}^{2}\right)$ dört köşesine tahta kazıklar çakılarak sınırları belirlenmiştir. Bu alan içerisine giren teraslar üzerinde 300 $\mathrm{m}$ uzunluk esas alınarak fidan çap $(\mathrm{mm})$ / boy $(\mathrm{cm})$ ölçümleri yapılmıştır. Fidan boyları işaretli latalar (Şekil 4a), çapları ise milimetrik çap ölçer (Şekil 4b) ile ölçülmüştür.

Şekil 4. Araştırma alanında fidanların a- boy ve b- çap ölçümü

Figure 4. a- height and b- diameter measurement of seedlings in the research area
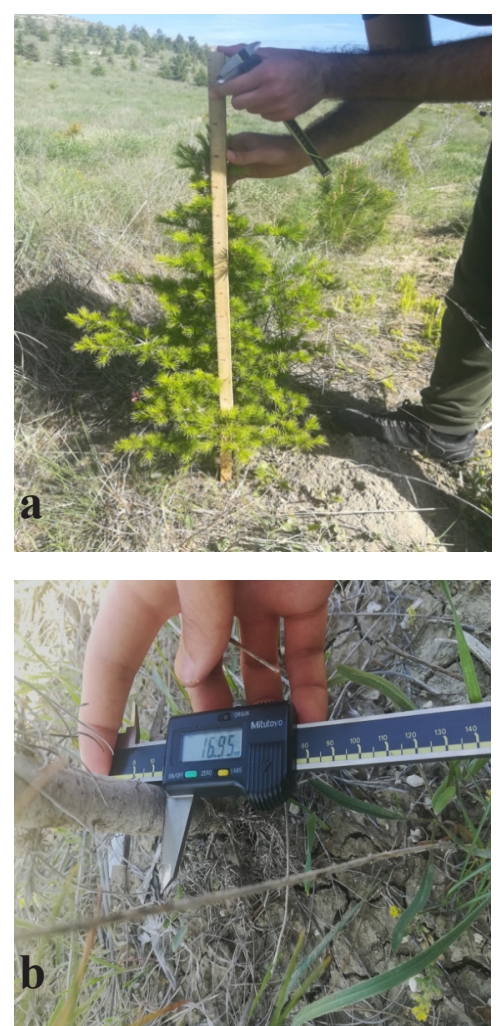
Toplam 237 fidan ölçümlere konu edilmiştir (Tablo 2). Ayrica toplam fidan sayıları, kuruyan ve canlı fidan sayıları ile fidanların morfolojik gelişim özellikleri (tepe kuruması, çarpıklık, sararma, dal kırılması) incelenmiştir. Ölçüm yapılan alanların yetişme ortamı özellikleri belirlenmiştir.

Tablo 2. Örnekleme noktalarında fidan türü ve toprak işleme yöntemine göre çap/boy için fidan adetleri dağılımı

Table 2. The distribution of seedlings numbers for diameter/length according to tree type and soil preparation techniques in the sampling points

\begin{tabular}{llc}
\hline & \multicolumn{1}{c}{ Grup } & Adet \\
\hline \multirow{4}{*}{ Ağaç } & Anadolu karaçamı (Çk) & 123 \\
Türleri & Kızılçam (Çz) & 77 \\
& Toros sediri (S) & 17 \\
& Yalancı akasya (YA) & 20 \\
\hline \multirow{4}{*}{ Toprak } & BUROR teras & 60 \\
İsleme & İukur dikim & 37 \\
Yöntemi riper alt toprak işleme + çift & 56 \\
& soklu pulluk & 54 \\
& Üst toprak işleme + çukur dikim & 24 \\
& BUROR teras & 60 \\
\hline & &
\end{tabular}

Belirlenen her örnek alanda toprak çukurları açılarak morfolojik özellikler incelenmiş ve genetik horizon esasına göre doğal yapısı bozulmuş toprak örneklemesi yapılmıştır. Toprak örneklerinde tekstür (Bouyoucos, 1951), elektriksel iletkenlik (EC), tuz ve toprak reaksiyonu (Rhoades, 1996), organik madde (Nelson ve Sommer, 1996), karbonat (kireç) (Richard ve Donald, 1996) analizleri yapılmıştır.
Çalışmada, toprak işleme şekli ve ağaç türünün fidan çap ve boy gelişimi üzerine etkisini belirlemek amaciyla tek yönlü varyans (one-way ANOVA) analizi ve Duncan test yöntemi kullanılmıştır $(\mathrm{p}<0,05)\left(\operatorname{SPSS}^{\circledR} 20.0\right)$.

\section{Bulgular}

\subsection{Araştırma alanı örnekleme noktaları toprak özellikleri}

\section{BUROR teras ve kızılçam+yalancı akasya dikimi (1. Örnek alan)}

a- Yüzey toprakları $(0-30 \mathrm{~cm})$ killi toprak sın1fında, orta taşlı olup granüler sütrüktedir. Kireç oran1 \%28 olup kireçce zengindir. Toprak reaksiyonu ( $\mathrm{pH}$ ) 7,2 olup bazik özellik göstermektedir. Topraklarda \%0,65 tuz ve $\% 1,16$ organik madde bulunmaktadır.

b- Orta derin topraklar $(30-60 \mathrm{~cm})$ killi, çok taş11, masif strüktedir. Kireç oran1 \%32 olup kireçce zengindir. Toprakların $\mathrm{pH}$ 7,6 bazik özelliktedir. Topraklarda \%0,96 tuz ve $\% 1,02$ organik madde bulunmaktadir.

c- Derin topraklar $(60+\mathrm{cm})$ ise killi balçık, orta taşlı granüler yapıdadır. Kireç oranı \%30 olup kireçce zengindir. Toprakların $\mathrm{pH} 7,5$ bazik özellikte. $\% 1,11$ tuz ve $\% 0,73$ organik madde bulunmaktadir (Tablo 3).

\section{Çukur dikimi ve kızılçam dikimi (2. Örnek alan)}

a- Yüzey toprakları kumlu balçık toprak sınıfında,

Tablo 3. Araştırma alanı örnekleme noktalarına ait bazı toprak özellikleri

Table 3. Some soil properties of sampling points of the research area

\begin{tabular}{|c|c|c|c|c|c|c|c|c|c|c|c|}
\hline \multirow{2}{*}{$\begin{array}{c}\text { Örnek } \\
\text { Alan } \\
\text { No }\end{array}$} & \multirow[b]{2}{*}{ Horizon } & \multicolumn{6}{|c|}{ Tane Dağglımı } & \multirow[b]{2}{*}{$\begin{array}{c}\mathrm{EC} \\
(\mathrm{dS} / \mathrm{cm})\end{array}$} & \multirow[b]{2}{*}{$\begin{array}{l}\text { Tuz } \\
(\%)\end{array}$} & \multirow{2}{*}{$\begin{array}{c}\mathrm{pH} \\
(1 / 5 \mathrm{Saf} \\
\mathrm{Su})\end{array}$} & \multirow{2}{*}{$\begin{array}{c}\text { Organik } \\
\text { Madde } \\
(\%)\end{array}$} \\
\hline & & $\begin{array}{l}\text { Derinlik } \\
(\mathrm{cm})\end{array}$ & $\begin{array}{l}\text { Kil } \\
(\%)\end{array}$ & $\begin{array}{l}\text { Toz } \\
(\%)\end{array}$ & $\begin{array}{c}\text { Kum } \\
(\%)\end{array}$ & Sinif & $\begin{array}{c}\text { Kireç } \\
(\%)\end{array}$ & & & & \\
\hline \multirow{3}{*}{1} & A & $0-13$ & 58 & 17 & 25 & $\mathrm{~K}$ & 28 & 1,033 & 0,65 & 7,2 & 1,16 \\
\hline & $\mathrm{BC}$ & $13-30$ & 51 & 21 & 26 & $\mathrm{~K}$ & 32 & 2,135 & 0,96 & 7,6 & 1,02 \\
\hline & $\mathrm{Cv}$ & $30+$ & 43 & 26 & 31 & KB & 30 & 2,089 & 1,11 & 7,5 & 0,73 \\
\hline \multirow{3}{*}{2} & A & $0-25$ & 31 & 25 & 44 & $\mathrm{KuB}$ & 23 & 2,006 & 0,98 & 7,3 & 1,32 \\
\hline & $\mathrm{BC}$ & $25-48$ & 25 & 40 & 35 & $\mathrm{KuB}$ & 28 & 1,965 & 1,26 & 7,6 & 0,98 \\
\hline & $\mathrm{Cv}$ & $48+$ & 15 & 30 & 55 & $\mathrm{KuB}$ & 30 & 2,658 & 1,53 & 7,6 & 0,66 \\
\hline \multirow{3}{*}{3} & $\mathrm{~A}$ & $0-23$ & 27 & 23 & 50 & KuKB & 19 & 1,658 & 1,16 & 6,8 & 1,91 \\
\hline & $\mathrm{BC}$ & $23-61$ & 17 & 32 & 51 & $\mathrm{KuB}$ & 26 & 1,963 & 1,54 & 7,4 & 0,19 \\
\hline & $\mathrm{Cv}$ & $61+$ & 27 & 21 & 52 & KuKB & 30 & 1,898 & 1,62 & 7,6 & 0,09 \\
\hline \multirow{3}{*}{4} & A & $0-28$ & 25 & 40 & 35 & $\mathrm{KuB}$ & 21 & 1,654 & 0,86 & 7,7 & 1,29 \\
\hline & $\mathrm{BC}$ & $28-58$ & 15 & 30 & 55 & $\mathrm{KuB}$ & 28 & 2,006 & 0,97 & 7,8 & 0,75 \\
\hline & $\mathrm{Cv}$ & $58+$ & 27 & 23 & 50 & KuKB & 29 & 2,019 & 1,36 & 7,8 & 0,54 \\
\hline \multirow{3}{*}{5} & A & $0-10$ & 23 & 33 & 44 & B & 30 & 2,156 & 0,99 & 6,9 & 1,03 \\
\hline & $\mathrm{BC}$ & $10-25$ & 35 & 25 & 40 & KB & 31 & 2,652 & 1,02 & 7,3 & 0,89 \\
\hline & $\mathrm{Cv}$ & $25+$ & 28 & 30 & 42 & $\mathrm{~KB}$ & 33 & 2,456 & 1,82 & 7,5 & 0,62 \\
\hline
\end{tabular}

K- kil, KB- killi balçık, KuB- kumlu balçık, KuKB- kummlu killi balçık, B- balçık 
orta taşlı olup strüktür tipi granüler yapıdadır. Kireç oranı \%24 olup kireçce zengindir. Toprakların reaksiyonu $\mathrm{pH} 7,3 ; \% 0,98$ tuz ve $\% 1,32$ organik madde bulunmaktadır.

b- Orta derin topraklar kumlu balçık toprak sınıfına girmektedir. Orta taşlı ve granüler yapıdadır. Kireç oran $1 \% 28,6$; $\mathrm{pH} 7,6$; $\% 1,26$ tuz ve $\% 0,98$ organik madde bulunmaktadır.

c- Derin topraklar ise kumlu balçık, çok taşlı ve masiftir. Kireç oranı \% 30; pH 7,6; \% 1,53 tuz ve \% 0,66 organik madde bulunmaktadır (Tablo 3 ).

\section{İkli riper ile alt toprak işleme+çift soklu pulluk ile teraslama ve Anadolu karaçamı-Toros sediri dikimi (3. Örnek alan)}

a- Yüzey toprakların tekstürü kumlu killi balçık, az taşlı ve strüktürü tipi granüler yapıdadır. Kireç oran1 \% 19; $\mathrm{pH} 6,8$; tuz $\% 1,16$ ve $\% 1,91$ organik madde bulunmaktadir.

b- Orta derin topraklar kumlu balçıklı, ve granüler yapıdadır. Kireç oranı \% 26; pH 7,4; tuz \% 1,54 ve $\% 0,19$ organik madde içermektedir.

c- Derin topraklar ise kumlu killi balçık toprak s1nıfında, orta taşlı olup strüktür tipi masiftir. Kireç oran1 \% 28; pH 7,6; tuz \% 1,62 ve \% 0,09 organik madde bulunmaktadır (Tablo 3).

\section{Çift soklu pulluk ile üst toprak işleme+çukur dikimi ve karaçam dikimi (4. Örnek alan)}

a- Yüzey toprakları kumlu balçıklı, az taşlı ve granüler yapıdadır. Kireç miktarı \% 21; pH 7,7; tuz \% 0,86 ve $\% 1,29$ organik madde içermektedir.

b- Orta derin topraklar kumlu balçık bünyeli, orta taşlı ve strüktürü tipi granüler yapıdadır. Kireç oran1 \% 28; pH 7,8; tuz miktar1 \% 0,97 ve $\% 0,75$ organik madde bulunmaktadır.

c- Derin topraklar ise kumlu killi balçık toprak s1nıfında, orta taşlı ve strüktür tipi masiftir. Kireç oran $1 \% 29 ; \mathrm{pH} 7,8$; tuz miktar $\% 1,36$ ve $\% 0,54$ organik madde bulunmaktadır (Tablo 3).

\section{BUROR teras ve karaçam dikimi (5. Örnek alan)}

a- Yüzey toprakları balçık toprak sınıfına girmektedir. Çok taşlı ve strüktür tipi granüler yapıdadır. Kireç oranı \% 30; pH 6,9; tuz miktarı \% 0,99 ve \% 1,03 organik madde bulunmaktadır.

b- Orta derin topraklar killi balçıklı, çok taşlı olup strüktür tipi masiftir. Kireç oranı \% 31; $\mathrm{pH} 7,3$; tuz miktar1 \% 1,02 ve \% 0,89 organik madde içermektedir. c- Derin topraklar ise killi balçıklı, çok bol taşl1, masif strüktürdedir. Kireç miktarı \% 33; pH 7,5; tuz miktar $\% 1,82$ ve $\% 0,62$ organik madde içermektedir (Tablo 3).

\subsection{Toprak hazırlığı ve ağaç türünün fidan çap/boy gelişimine etkileri}

Fidanların çap ölçüm sonuçları üzerine yapılan tek yönlü varyans analizi sonucunda dikilen ağaç türleri arasinda $(F$ hesap $=5,572$ ve $p<0,05)$ ve toprak işleme yöntemi ( $F$ hesap $=3,97$ ve $p<0,05)$ bak1mından istatistiki olarak anlamlı fark olduğu belirlenmiştir. Buna göre toprak işleme şekli ve ağaç türünün fidanlarda çap/boy gelişmi bakımından önemli düzeyde etkili olduğu belirlenmiştir.

Tüm ağaç türleri bakımından fidan çap gelişimleri incelendiğinde en yüksek çap ortalaması yalancı akasya türündedir.

İbreli türler içerisinde çap ortalaması en yüksek karaçam, en düşük ise sedir türünde olduğu belirlenmiştir (Tablo 4).

Tablo 4. Ağaç türlerine göre fidanlarda çap ölçüm değerlerine ait Duncan testi sonuçları

Table 4. Duncan test results of diameter measurement values of seedlings according to tree species

\begin{tabular}{|c|c|c|c|c|}
\hline Fidan Türleri & Adet & & Alt Gruplar & \\
\hline Toros Sediri & 17 & $12,8^{\mathrm{a}}$ & & \\
\hline Kızılçam & 123 & & $16,9^{b}$ & \\
\hline A. Karaçamı & 77 & & \multicolumn{2}{|l|}{$20,8^{c}$} \\
\hline Yalancı Akasya & 20 & & & $27,8^{\mathrm{d}}$ \\
\hline
\end{tabular}

Toprak işleme yöntemleri açısından bakıldığında, fidanlarda en yüksek çap ortalaması BUROR terasta dikim yapılan kızılçam (1. örnek alan) gurubunda, en düşük çap ortalamasının ise ikili riper ile alt toprak işleme + çift soklu pulluk ile teraslama (3. örnek alan) gurubunda olduğu görülmektedir (Tablo 5).

Tablo 5. Toprak işleme türüne göre fidanlarda çap (mm) değerlerine ait duncan testi sonuçları

Table 5. Duncan test results for diameter values $(\mathrm{mm})$ of seedlings according to site preparation techniques

\begin{tabular}{lcccc}
\hline Toprak İşleme Yöntemi & Adet & \multicolumn{2}{c}{ Alt Gruplar } \\
\hline İkili riper+Çift Soklu & 56 & $15,6^{\mathrm{a}}$ & & \\
Pulluk & & & & \\
BUROR Teras (Çk) & 60 & $16,1^{\mathrm{a}}$ & & \\
Çukur Dikim & 37 & $18,6^{\mathrm{a}}$ & $18,6^{\mathrm{b}}$ & \\
Üst Toprak & 24 & & $19,5^{\mathrm{b}}$ & \\
İşleme+Çukur Dikim & 24 & & & $24,5^{\mathrm{c}}$ \\
BUROR Teras (Çz) & 60 & & &
\end{tabular}

Not: $a<b<c$ 
Fidan boyları üzerine yapılan tek yönlü yapılan varyans analizi sonucunda, ağaç türleri arasında ( $\mathrm{F}$ hesap $=39,572$ ve $p<0,05)$ ve toprak işleme yöntemleri arasinda $(\mathrm{F}$ hesap $=11,069$ ve $\mathrm{p}<0,05)$ istatistiksel olarak anlamlı fark olduğu belirlenmiştir.

Ağaç türlerine göre fidanların boy gelişimleri arasındaki fark incelendiğinde en yüksek boy ortalamasının yalancı akasya türünde, ibreli türler arasında ise en yüksek boy ortalamasının kızılçam, en düşük ise sedir türlerinde olduğu görülmüştür (Tablo 6).

Tablo 6. Ağaç türlerine göre fidanlarda boy (cm) ölçüm değerlerine ait Duncan testi sonuçları

Table 6. Duncan test results of height $(\mathrm{cm})$ measurement values of seedlings according to tree species

\begin{tabular}{|c|c|c|c|c|}
\hline Fidan Türleri & Adet & & Alt Gruplar & \\
\hline Toros Sediri & 17 & $47,2^{\mathrm{a}}$ & & \\
\hline A. Karaçamı & 123 & & $63,2^{\mathrm{b}}$ & \\
\hline Kız1lçam & 77 & & \multicolumn{2}{|l|}{$83,2^{\mathrm{c}}$} \\
\hline Y. Akasya & 20 & & & $166,2^{\mathrm{d}}$ \\
\hline
\end{tabular}

İstatistiksel analiz sonucunda ibreli türler arasında 1. örnek alanda BUROR terasta dikimi yapılan kızılçam türünün en yüksek boy gelişimi yaptığ 1 belirlenmiştir.

Tüm toprak işleme yöntemleri içerisinde ikili riper ile alt toprak işleme + çift soklu pulluk sahasında dikilen fidanların en düşük boy gelişimi yaptıkları görülmüştür (Tablo 7).

Diğer taraftan tüm toprak işleme yöntemleri içerisinde BUROR teras toprak işleme yönteminde fidanların daha yüksek boy gelişimi sağladıkları anlaşılmıştır.

Tablo 7. Toprak işleme yöntemine göre fidanlarda ölçülen boy $(\mathrm{cm})$ değerlerine ait Duncan testi sonuçları Table 7. Duncan test results for height $(\mathrm{cm})$ measurement values in seedlings according to site preparation techniques

\begin{tabular}{llll}
\hline \multicolumn{2}{l}{ Toprak İşleme Yöntemleri } & Adet & \multicolumn{2}{c}{ Alt Gruplar } \\
\hline İkili Riper + Çift Soklu & 56 & $55,7^{\mathrm{a}}$ & \\
$\begin{array}{l}\text { Pulluk } \\
\text { Üst Toprak İşleme+Çukur }\end{array}$ & 24 & $61,8^{\mathrm{a}}$ & \\
Dikim & 37 & $64,8^{\mathrm{a}}$ & \\
Çukur Dikim & 60 & $66,3^{\mathrm{a}}$ & \\
BUROR Teras (Çk) & 60 & & $122,1^{\mathrm{b}}$ \\
BUROR Teras (Çz) & & & \\
\hline
\end{tabular}

Not: $a<b$

Tüm örnek alanlarda yapılan çap/boy ölçümleri so- nucunda en yüksek başarı BUROR teras (5. örnek alan), en düşük başarı ise ikili riper ile alt toprak işleme + çift soklu pulluk ile teraslama yapılan sahalarda olduğu sonucuna varılmıştır.

\section{Tartışma ve Sonuç}

Araştırma alanının yağış miktarı 400-500 mm arasında olup, yarı kurak, tuz/jipsli ana kayalı, bitki örtüsü genellikle bozkırdır. Çankırı toprakları, Oligosen ve Miosen dönemi tuzlu, sodyumlu ve jipsli gevşek tortullar oluşmuştur (Atalay, 2010; Atalay, 2011). Çankırı, İç Anadolunun çölleşme riski taş1yan bölgeleri içerisindedir (ÇEM, 2013). İç Anadolu Bölgesi toprak tekstürleri çoğunlukla killi balçık ya da balçıklı kil olup, kil topraklar da mevcuttur. Toprak derinlikleri de oldukça değişkendir (Atalay, 2015). Araştırma alanı toprakları da ince tekstürlü killi topraklardan oluşmaktadır. Bu özellikleri ile araştırma alanı olarak seçilen ağaçlandırma sahası bitki gelişimi bakımından oldukça olumsuz ekolojik koşullara sahiptir.

Yarı kurak alanlarda aşırı otlatma ve yanlış arazi kullanımı toprak tahribatının temel nedenleridir. $\mathrm{Bu}$ gibi alanlarda Ah horizonları erozyonla taŞınmış, toprakların organik madde içerikleri de oldukça düşüktür (ÇEM, 2013; OGM, 2015). Araştırma alanı, geçmişte bozuk mera niteliğinde iken sonradan ağaçlandırmaya konu edilmiştir.

Jipsli topraklar, organik madde bakımından fakir (FAO, 1990), pH değeri nötr civarındadır (FAO, 1990; Parsons, 1976). Araştırma alanı topraklarında da organik madde içeriği düşük, toprak reaksiyonları alkali özellik göstermiştir.

Toprak işleme şeklinin fidanların çap gelişimi üzerine etkisi bakımından istatistiksel bakımdan önemli düzeyde fark ortaya çıkmıştır. Tüm örnek alanlar bakımından BUROR terasta Çz + YA dikimi yapılan saha, diğer toprak işleme türlerine göre daha yüksek çap ortalamasına sahiptir. Tüm sahalar bakımından çap ortalamalarının sırasıyla yalancı akasya, kızılçam ve karaçam türlerine aittir. Gülcü ve Çelik (2016)'da yaptıkları benzer bir araştırmada toprak işleme şeklinin fidanların çap gelişimi üzerine etkili olduğu sonucuna ulaşmışlardir.

Türlerin kendi aralarında çap ortalamaları kıyaslandığında hepsinin farklı çap grupları içerisinde yer aldığı, en yüksek ortalamanın yalancı akasya türünde, ibreli türler kendi arasında değerlendirildiğinde en yüksek çap ortalaması Anadolu karaçamı türünde, en düşük ortalama ise Toros sediri türündedir. Gülcü ve Çelik (2016)'da yaptıkları çalışmada, Toros sedirinin en yüksek, karaçamın 
ise en düşük çap gelişimi gösterdiğini ifade etmişlerdir.

Farklı toprak işleme yöntemlerine göre türlerin gelişimleri incelendiğinde türlere ve toprak işleme şekline göre gruplar arasında önemli istatistiksel fark ortaya çıkmıştır. Birçok araştırmada (Tolay, 1988; Çepel, 1985; Zoralioğlu, 1988; Boydak ve Zoralioğlu, 1992) yarı kurak mıntıkalarda, sıkışmış toprakların derin işlendiğinde, dikim başarısının arttığı ortaya konulmuştur. Araştırma sonuçlarımız çap ortalamarı bakımından kızılçam türünün BUROR terasta, karaçam türünün ise üst toprak işleme+çukur dikim tipi arazi hazırlığında daha yüksek başarı sağladığını göstermiştir. $\mathrm{Bu}$ durumda ağaçlandırma çalışmalarında dikilecek türe göre farklı toprak işleme yönteminin uygulanmas1 gerekmektedir. Boydak ve Zoralioğlu (1992)'de yarı kurak sahalarda toprağın en az $45 \mathrm{~cm}$ işlemesi gerektiğini belirtmişlerdir. Araştırmamazın sonuçlarında da BUROR teras ile derin toprak işlemenin fidan gelişiminde daha olumlu olduğu ortaya konulmuştur. Bayburt yöresinde yapılan ağaçlandırma çalışmalarında, derin toprak işlemenin dikim başarısını artırdığ 1 belirlenmiştir (Güvendi ve ark., 2019).

Çukur dikim ile üst toprak işleme+çukur dikim sahalarında fidan gelişim özellikleri benzer sonuçlar vermiştir. Bu durumda toprak yüzeyinde sıkışma, diri örtü sorunu veya benzer dikim sorunu olmayan çukur dikim sahalarında kısmı veya tam alanda üst toprak işlemesi yapılmayabilir.

Toprak işleme yöntemi ve ağaç türünün fidanların boy gelişimi üzerine etkili olduğu belirlenmiştir. Fidanların boy gelişiminin en yüksek BUROR teras toprak işleme şeklinde, türler bakımından ise sırasıyla yalancı akasya, kızılçam ve karaçam türlerindedir. İbreli türler içerisinde en yüksek boy gelişimi kızılçam, en düşük Toros sediri türündedir. Ülkemizin kurak ve yarıkurak bölgelerinde kalıntı ormanlar ve ağaç toplulukları bölgenin geçmişi hakkında önemli bilgiler sunmaktadır (Aytuğ ve Görcelioğlu, 1993; Boydak ve ark. 2010). Türkiye'de yarıkurak bölgelerde yürütülen araştırmalarda (Yaltırık, 1984; Odabaşı ve Boydak, 1984; Boydak, 1986, Ürgenç, 1998; Kocaçınar ve Ok, 2010) ağaçlandırma çalışmalarında arazi hazırlığı ve tür seçiminin önemi üzerinde durulmaktadır.

Ağaçlandırma sahası örnek alanlar içerisinde en yüksek başarı BUROR teras, en düşük başarı ikili riper ile alt toprak işleme + çift soklu pulluk ile teraslama alanlarındadır. Boydak ve Zoralioğlu (1992) yarı kurak alanlarda ağaçlandırma çalışmalarında derin ve alt toprak işlemesinin başarıyı artırdığını ortaya koymuşlardır.
Jipsofil bitkiler otsu ya da bodur çalı formundadır (Parsons, 1976). Kurak ve yarı kurak iklim bölgelerinde görülen tuz ve jips bitki yaşamı için yaşamsal stres faktörüdür (Guerrero Campo ve ark., 1999). Jips, toprak yüzeyinde kabuk oluşumuna neden olduğu için fide ve tohum gelişimini engellemektedir (Escudero ve ark., 2000; Meyer, 1986; Meyer ve García-Moya, 1989). Bu nedenlerle jipsli sahalarda yürütülecek ağaçlandırma çalışmalarında toprak hazırlığı, tür seçimi ve dikim sonrası fidan bakımı dikkatle yapılmalıdır. Nitekim Boydak ve Zoralioğlu (1992) yoğun bakım yapılmış dikim sahalarında başarı oranının daha yüksek olduğunu ortaya koymuşlardır.

Çankırı yöresinde tuzlu ve jipsli sahalar, özel bir korumaya ihtiyaç duymayan, verimsiz toprağa sahip alanlar olarak algılanmaktadır. Oysa bu sahalar yerel veya bölgesel floristik çeşitliliğe büyük oranda katkısından dolayı korunmaya değer habitatlar olarak kabul edilmektedirler (Akpulat ve Çelik, 2005; Matesanz ve ark., 2009; Mota ve ark., 2017). “Çankırı'nın Jipsli Tepeleri” Türkiye'nin Önemli Bitli Alanı olarak belirlenmiştir. Bu nedenle bu tip ekosistemlerde ağaçlandırma çalışmaları için alan ve tür seçimi konusunda daha dikkatli olunmalıdır. Floristik yapıyı bozan ve yerel ekolojik koşullara uyum sağlayamayan türler ağaçlandırmalarda tercih edilmemelidir.

Çankırı yöresinde, ağaçlandırma çalışmalarında bitki gelişimini engeleyecek kuraklık, yüksek kireç, düşük organik madde içeriği, tuz ve jips gibi özelliklerin biri veya birkaçı aynı saha içerisinde görülebilmektedir. Bu nedenle, bu yörede yürütülecek erozyon kontrolü ve ağaçlandırma çalışmalarında başarıyı artırmak için 1- derin toprak işleme yapılmalı, 2- dikilecek ağaç türüne göre en uygun toprak işleme yöntemi belirlenmeli, 3- yerel türler tercih edilmeli, 4- yörede yetiştirilmiş fidanlar kullanılmalı ve 5- uygun koşullarda yapraklı ve çalı türleri de tercih edilmelidir.

\section{Teşekkür}

Bu araştırma, TÜBİTAK 2209-A 1919B011802530 No.lu Üniversite Öğrencileri Yurt İçi Araştırma Projeleri tarafından desteklenmiştir. Veri temini ve arazi çalışmalarında yardımcı olan Çankırı Orman İşletme Müdürlüğü'ne, Ağaçlandırma ve Toprak Muhafaza Şefi Burak Özkan'a ve arazi çalışmalarında yardımcı olan Ç.K.Ü., Orman Fakültesi Dr. Öğr. Üyesi Mehmet Said Özçelik'e, istatistiksel hesaplamaları için Ç.K.Ü., Orman Fakültesi öğretim üyesi Doç. Dr. İlker Ercanlı'ya teşekkür ederiz.

\section{Kaynaklar}

Akpulat, H.A., Çelik, N., 2005. Flora of gypsum areas in 
Sivas in the eastern part of Cappadocia in Central Anatolia, Turkey. Journal of Arid Environments. 61: 27-46.

Akyürek, B., Akbaş, B., Değer, Z., 1988. 1/100.000 Ö1çekli Açınsama Nitelikli Türkiye Jeoloji Haritaları Servisi, Çankırı E-16 Paftası, MTA Gn. Md. Jeoloji Etüd Dairesi, Ankara.

Alphen, J. G., Rios Romero, F., 1971. Gypsiferous soils notes on their characteristics and management. Bulletin/ International Institute for Land Reclamation and Improvement-Wageningen, The Netherlands.

Atalay, İ., 2010. Tuzlu-alkali anamateryallerin ortam bozulması ve çölleşme üzerindeki etkileri. Çölleşme ile Mücadele Sempozyumu, 17-18 Haziran 2010, Çorum. Tebliğler Kitabı, s: 14-19.

Atalay, İ., 2011. Türkiye‘de yarıkurak bölgelerin ekolojik özellikleri ve ağaçlandırmada tür seçimi. Kurak ve Yarıkurak Alan Yönetimi Çalıștayı Sonuç Bildirgesi ve Bildiriler, 5-8 Aral1k 2011, Ürgüp-Nevşehir, s: 202-241.

Atalay, İ., 2014. Türkiye'nin Ekolojik Bölgeleri (Genişletilmiş 2. Bask1). Meta Basım Matbaacılık Hizmetleri, İzmir. s: 20-36.

Atalay, İ., 2015. Toprak Amenajmanı, Türkiye Topraklarının Oluşumu ve Kullanımı. Erşahin, S., Öztaş, T., Nam1, A., Karahan, G. (Ed.), Gazi Kitap Evi, ISBN: 978-605344-278-3, Ankara, s: 19-94.

Atay, S., Doğruöz, D., Orhun, C., Dağdeviren, Ö., 2009. ÖBANET Gönüllü Klavuzu, Dönence Basım ve Yayın Hizmetleri, http://obanettr.org/images/pdf/Obanet kilavuz.pdf, ISBN/EAN: 978-90-814408-2-0, İstanbul. s: 11-12, (Ziyaret Tarihi: 08.03.2021).

Aytuğ, B., Görcelioğlu, E., 1993. Anadolu bitki örtüsünün geç Kuaterner'deki gelişimi. I.Ü. Orman Fakültesi Dergisi, B(3-4): 27-46.

Birgili, Ş., Ünalan, G., Yoldaş, R., 1975. Çankırı-Çorum Havzası'nın Jeolojisi ve Petrol Olanakları, MTA Genel Müdürlüğü Raporu, Rap., No: 5621, Ankara.

Blumenthal, M., 1948. Bolu Civarı ile Aşağı Kızılırmak Mecras1 Arasındaki Kuzey Anadolu Silsilesi'nin Jeolojisi, MTA Genel Müdürlüğü Raporu, Rap No. 2026, Ankara.

Bouyoucos, G.J.A., 1951. Recalibration of the hydrometer for making mechanical analysis of soil. Agronomy Journal (Journal of American Society of Agronom) 43: 434-438.

Boydak, M., 1986. Güneydoğu Anadolu Projesi (GAP) ve GAP'ta ormancılı̆̆ın yeri. I.Ü. Orman Fakültesi Dergisi, B36(2): 75-93.

Boydak, M., Zoralioğlu T., 1992. Eskişehir-Karasakal yöresi yarı kurak alanların ağaçlandırılmasında makineli arazi hazırllğ 1 yöntemleri üzerine araştırmalar. $\dot{I}_{s-}$ tanbul Üniversitesi, Orman Fakültesi Dergisi (JFFIU), A(42): 2.

Boydak, M., Ertaş, A., Çalışkan, S., 2010. Kurak ve yar1- kurak bölgelerin ağaçlandırılmasında ilkeler ve uygulama esasları. Çölleşme ile Mücadele Sempozyumu, 17-18 Haziran 2010, Çorum, s: 370-382.

Cañadas, E.M., Ballesteros, M., Valle, F., Lorite, J., 2013. Does gypsum influence seed germination? Turkish Journal of Botany. 38: 141-147.

ÇEM, 2013. Kurak ve Yarı Kurak Alanlarda Ağaçlandırma Rehberi, T.C. Orman ve Su İşleri Başkanlığı, Çölleşme ve Erozyonla Mücadele Genel Müdürlüğü, Ankara. $190 \mathrm{~s}$.

Çepel, N., 1985. Ağaçlandırma çalışmalarında uygulanan arazi hazırlığına ilişkin mekanizasyonun ekolojik sonuçlar1. İstanbul Üniversitesi Orman Fakültesi Dergisi, $\mathrm{B}(3-5): 1$.

Escudero, A., Iriondo, J. M., Olano, J. M., Rubio, A., Somolinos, R.C., 2000. Factors affecting establishment of a Gypsophyte: The case of Lepidium subulatum (Brassicaceae). American Journal of Botany. 87: 861-871.

FAO, 1990. Management of Gypsiferow Soils. Food and Agriculture Organization (FAO) Soils Bulletin, Rome, Italy. $62 \mathrm{p}$.

Gökmen, B., 2007. Çankırı ili coğrafyası. Ankara Üniversitesi, Sosyal Bilimler Enstitüsü, Doktora Tezi, Ankara.

Göl, C., 2002. Çankırı-Eldivan yöresinde arazi kullanım türleri ile bazı toprak özellikleri arasındaki ilişkiler. Ankara Üniversitesi, Fen Bilimleri Enstitüsü, Doktora Tezi. Ankara.

Guerrero Campo, J., Alberto, F., Maestro, Mart1'nez, M., Hodgson, J., Montserrat Mart1', G., 1999. Plant community patterns in a gypsum area of NE Spain. II. Effects of ion washing on topographic distribution of vegetation. Journal of Arid Environments, 41: 411-419.

Güneş, A., Alpaslan, M., İnal, A. 2010. Bitki Besleme ve Gübreleme. Ankara Üniversitesi, Ziraat Fakültesi Yayınları, Yayın No: 1581, Ders kitabı: 533. ISBN:978-975482-878-8, Ankara.

Güvendi, E., Kahyalıŏ̆lu, N., Ertuğrul, M.H., Karahan, S., 2019. Ağaçlandırma faaliyetlerinin başarı oranları ve sebepleri (Bayburt örneği), III. International Mediterranean Forest and Environment Symposium, IMFES, 0305 Ekim 2019, Kahramanmaraş. s: 173-176.

Kantarcı, M. D., Narlığlu, H., Özder, H., Çakıroğlu, İ.E., 2010a. Ankara ağaçlandırmaları. Çölleşme ile Mücadele Sempozyumu, Tebliğler Kitabı, 17-18 Haziran 2010, Çorum. s: 110-120.

Kantarc1, M. D., Narlıŏlu, H., Kavlak, T., Metġn, C., Koçak, T., Uzun, H.B., 2010b. Konya, Karaman, Niğde, Aksaray illerinde ağaçlandırma ve toprak koruma çalıșmaları. Çölleşme ile Mücadele Sempozyumu, Tebliğler Kitabı, 17-18 Haziran 2010, Çorum. s: 121-129.

Kocaçınar, F., Ok, T., 2010. Orta Anadolu'da çölleşme ile mücadelede kullanılabilecek bazı odunsu türlerin ekofizyolojik özellikleri. Çölleşme ile Mücadele Sem- 
pozyumu 17-18 Haziran 2010 Çorum. s: 137-148.

Matesanz, S., Escudero, A., Valladares, F., 2009. Influence of three cooccurring global change drivers on the survival, growth, phenology and reproduction of a Mediterranean shrub. Ecology, 90: 2609-2621.

Meyer, S.E., 1986. The ecology of gypsophile endemism in the Eastern Mojave Desert. Ecology, 67: 1303-1313.

Meyer, S., García-Moya, E., 1989. Plant community patterns and soils moisture regime in gypsum grasslands of North Central Mexico. Journal of Arid Environments, 16 : 147-155.

MGM, 2019. Çankırı Meteoroloji İstasyonu İklim Verileri. Tarım ve Orman Bakanlığı, Meteoroloji Genel Müdürlüğü, Ankara.

Mota, J.F., Sola, A.J., Dana, E.D., 2003. Plant succession in abandoned gypsum quarries in SE Spain. Phytocoenologia, 33: 13-28.

Mota, J. F., Garrido-Becerra, J. A.; Merlo, M. E., MedinaCazorla, J. M., Sánchez-Gómez, P., 2017. The Edaphism: Gypsum, Dolomite and Serpentine Flora and Vegetation. In: Loidi J, editor. The vegetation of the Iberian Peninsula. New York: Springer, Cham. Inc; pp: 277-354.

Nelson, D.W., Sommer, L.E., 1996. Methods of Soil Analysis. Part 3. Chemical Methods. Soil Science of America and American Society of Agronomy. SSSA Book Series No.5. Madison-USA, pp: 961-1011.

Odabaşı, T., Boydak, M., 1984. Güneydoğu Anadolu Projesi (GAP) ve GAP'ta ormancılı̆̆ın yeri ve katkıları. I. Ü. Orman Fakültesi Dergisi, B34(3): 33-48.

OGM, 2011-2030. Çankırı Orman İşletme Şefliği Fonksiyonel Amenajman Plan1. Orman Genel Müdürlügü (OGM), Ankara Orman Bölge Müdürlüğü, Çankırı Orman İşletme Müdürlüğü, Çankırı.

OGM, 2013. "28. Mekanize Piyade Komutan Yardımc1lığı Erozyon Kontrol Uygulama Projesi”. Orman Genel Müdürlüğü (OGM), Ankara Orman Bölge Müdürlüğü, Çankırı Orman İşletme Müdürlügüu, Çankırı Ağaçlandırma ve Toprak Muhafaza Şefliği, Çankırı.

OGM, 2015. Türkiye Orman Varlığı. T.C. Orman ve Su İşleri Bakanlığı, Orman Genel Müdürlüğü, Ankara. 23s.
Oyonarte, C., Sanchez, G., Urrestarazu, M., Alvarado. J J., 2002. A comparison of chemical properties between gypsophile and nongypsophile plant rhizospheres. Arid Land Research and Management, 16: 47-54.

Palacio, S., Escudero, A., Montserrat-Marti, G., Maestr,o M., Milla, R., Albert, M.J., 2007. Plants living on gypsum: beyond the specialist model. Annals of Botany, 99: 333-343.

Palacio., S., Escudero, A., Montserrat-Marti, G., Maestro, M., Milla, R., Albert, M., 2007. Plants living on gypsum: beyond the specialist model. Annals of Botany, 99: 333343.

Parsons. R.F., 1976. Gypsophily in plants. A review, American Midland. Naturalist. 96(1): 1-20.

Pueyo, Y., Alados, C.L., Barrantes, O., Maestro, M., Komac, B., 2007. Gypsophile vegetation patterns under a range of soil properties induced by topographical position. Plant Ecology. 189: 301-311.

Rhoades, J.D., 1996. Methods of Soil Analysis. Part 3. Chemical Methods. Soil Science of America and American Society of Agronomy. SSSA Book Series No.5. Madison-USA, pp: 417-437.

Richard, H.L., Donald, L.S., 1996. Methods of Soil Analysis. Part 3. Chemical Methods. Soil Science of America and American Society of Agronomy. SSSA Book Series No. 5. Madison-USA, pp: 437-475.

Tuttu, G., Akkemik, Ü., 2017. Çankırı-Korubaşı tepe ve civarındaki jipsli alanların florası. Ot Sistematik Botanik Dergisi, 24(1): 45-88.

Ürgenç, S., 1998. Ağaçlandırma Tekniği (Yenilenmiş ve Genişletilmiş İkinci Bask1). İ.Ü. Orman Fakültesi Yay1n1, Y. No.3994\441, İstanbul. 600s.

Yaltırık, F., 1984. Türkiye Meşeleri Teşhis Kılavuzu. Tarım, Orman ve Köy işleri Bakanlığı Orman Genel Müdürlüğü Yayını, Yenilik Basımevi, İstanbul.

Yang, Y.W., Newton, R.J., Millerf., R., 1990. Salinity tolerance in Sorghum. I hole Plant Response to Sodium Chloride in S. Bicolor and S. halepense. Crop Science, 30: 755-781. 